\title{
Erratum to: Characterization of photosystem II heterogeneity in response to high salt stress in wheat leaves (Triticum aestivum)
}

\author{
Pooja Mehta $\cdot$ Suleyman I. Allakhverdiev \\ Anjana Jajoo
}

Published online: 3 March 2011

(C) Springer Science+Business Media B.V. 2011

\section{Erratum to: Photosynth Res (2010) 105:249-255 DOI 10.1007/s11120-010-9588-y}

There was incorrect information in the second, third and fourth full sentences on page 253 of the orginal publication ('As is evident...'). They should read as follows:

The lifetime of the fastest alpha component was $0.26 \mathrm{~ms}$ and contributed $67 \%$ of the total amplitude. The beta component was about 7 -fold slower (life time $\sim 1.9 \mathrm{~ms}$ ) and it was responsible for $32 \%$ of the total amplitude. The gamma component was very slow with lifetime of $\sim 7 \mathrm{~ms}$ and small, being only $1 \%$ of the total amplitude in control leaves. These results are in agreement with those obtained on pea leaves, determined with those obtained on pea leaves, determined with the same method (Toth and Strasser 2005).

\section{Reference}

Toth SZ, Strasser RJ (2005) The specific rate of QA reduction and photosystem II heterogeneity. Proceedings of the 13th international congress on photosynthesis, Montreal, Canada, pp 198-200

The online version of the original article can be found under doi:10.1007/s11120-010-9588-y.

P. Mehta · A. Jajoo (凹)

School of Life Science, Devi Ahilya University, Indore 452017,

MP, India

e-mail: anjanajajoo@hotmail.com

\section{S. I. Allakhverdiev}

Institute of Plant Physiology, Russian Academy of Sciences,

Botanicheskaya Street 35, Moscow 127276, Russia

S. I. Allakhverdiev

Institute of Basic Biological Problems, Puschino,

Moscow Region 142290, Russia 